\title{
İstanbul Mutfağında Yeni Dünya Lezzetleri: Domates, Biber, Patates*
}

\section{Özge Samancı**}

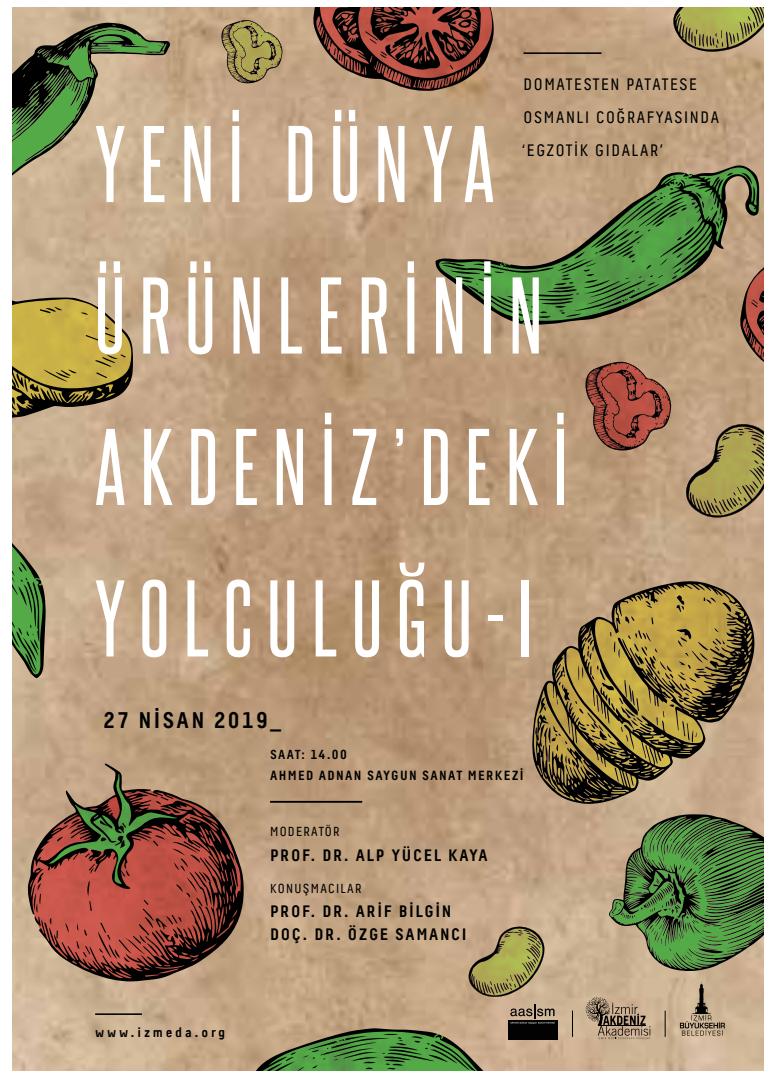

15. yüzyıldan 20. yüzyıl başlarına değin Osmanlı İmparatorluğu'nun başkenti olan İstanbul, bir yandan saray kültürü, diğer yandan kentin kendi içinde barındırdığı kültürel çeşitlilik ve başkent olmanın getirdiği ticari, kültürel ve ekonomik dinamikler ile zengin bir mutfak kültürü oluşturmuştur. Seçkin İstanbul mutfağında kullanılan malzemeler, tercih edilen lezzet ve tatlar yüzyıllar içinde değişerek farklılık göstermiştir.

İstanbul mutfak kültüründe damak tadının değişim yolculuğunda, tüketimi on 18. yüzylıın sonlarından itibaren başlayan ve esas olarak 19. yüzyılda yaygınlaşan Amerika kökenli yenilebilir bitkiler önemli rol oynamıştır. Domates, yeşil biber, kırmızı biber, patates, sakız kabağı, bal kabağı, fasulye, mısır, karnabahar, yer elması, vanilya, kakao ve yenibahar, tüm bu Amerika kıtasına özgü bitkiler, on altıncı yüzyıldan sonra eski kıtalara ulaşmış ve zaman içinde Avrupa, Asya ve Afrika'nın mutfak kültürlerine uyum sağlamıştır.'

Bu metin, İzmir Akdeniz Akademisi tarafından Ahmed Adnan Saygun Sanat Merkezi'nde 27 Nisan 2019'da düzenlenen Yeni Dünya Ürünlerinin Akdeniz'deki Yolculuğu başlıklı konferansta yapılan sunuşa dayanmaktadır.

Özyeğin Üniversitesi, Gastronomi ve Mutfak Sanatları Bölümü 
Amerika kökenli bu yenilebilir bitkiler Osmanlı döneminde İstanbul mutfağına oldukça geç bir dönemde, 18. yüzyıldan itibaren gelmiş ve zaman içinde Türk mutfak kültürünün bir parçası olmuşlardır. Osmanlı saray mutfaklarının muhasebe kayıtlarına göre Amerika menşeli bir meyve olan domates saraya ilk olarak kavata adıyla yeşil renkli bir çeşidi ile 1690'larda girmiştir. ${ }^{2}$

18. yüzylla ait yemek risaleleri ve saray mutfak defterlerine göre bu dönemde İstanbul mutfağında domates tüketimi yaygınlaşmamıştır. 19. yüzyılın başlarından itibaren ise hem kırmızı hem de yeşil domatesin Osmanlı saray mutfaklarının muhasebe defterlerinde yer almaya başladığı görülmektedir. ${ }^{3}$

Illk baskısı 1844'te gerçekleşen Melceü’t-Tabbâhîn (Aşçıarın Sığınağı) adlı Osmanlı Türkçesi yemek kitabında içinde domates bulunan en fazla sekiz yemek tarifi bulunmaktadır. Yeşil domates
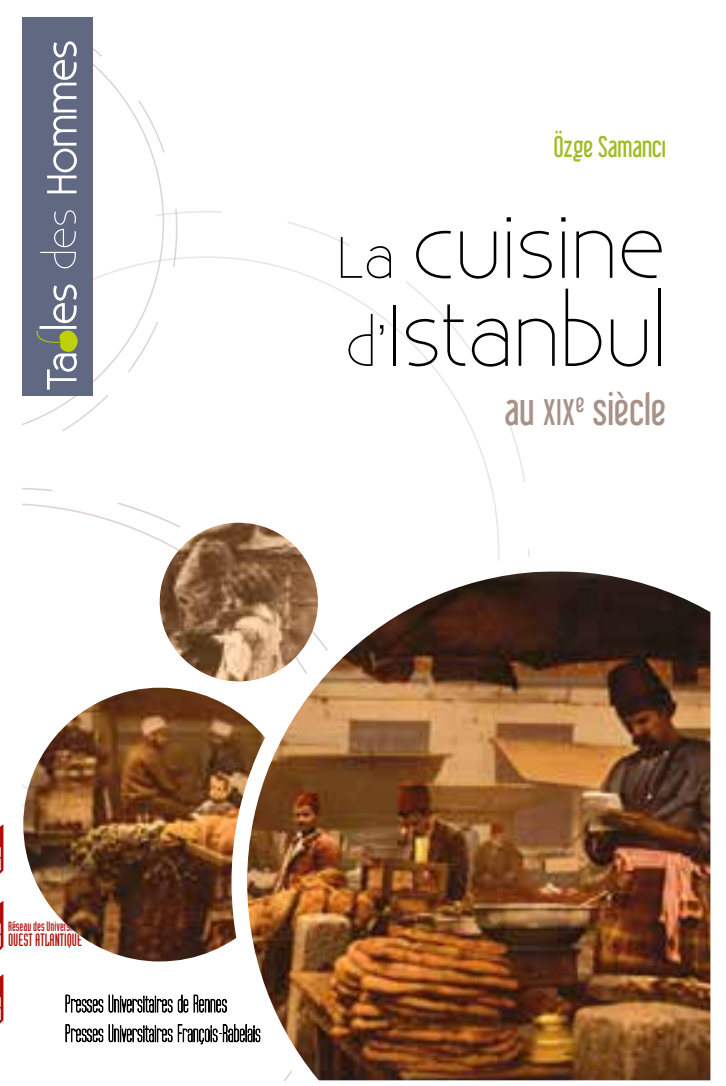

Özge Samancı'nın 19. Yüzyılda İstanbul Mutfağı başıı̆ını taşıyan çalışması 2015’te Fransa'da yayımlandı.

1 Özge Samancı, "Vegetable Patrimony of the Ottoman Culinary Culture", Proceedings of the IVth International Congress of Ethnobotany (ICEB 2005) içinde, der. Z. Füsun Ertuğ (İstanbul: Ege Yayınları, 2006), 565-570.

2 Tülay Artan, "Aspects of the Ottoman Elite's Food Consumption: Looking for 'Staples', 'Luxuries' and 'Delicacies' in a Changing Century", Consumption Studies and the History of the Ottoman Empire 1550-1922: An Introduction içinde, der. Donald Quataert (New York: State University of New York Press, 2000), 107-200.

3 Özge SamancI, La Cuisine d'Istanbul au XIXe siècle (Rennes: Presses Universitaires de Rennes, Presses Universitaires François-Rabelais, 2015), 87. 
daha ziyade ekşi yemeklerde ve turşuda kullanıırıken, kırmızı domates beş tarifte yer alır: Şiş kebap, domatesli koyun yahnisi, domatesli pilav, sebze türlüsü ve domates salatası. ${ }^{4}$ Domates on 19. yüzyılda Osmanlı coğrafyasında ziraatı yapılan bir ürün haline gelmiş ve mutfakta kullanımı da artmıştır.

1850'lerden itibaren saraya ait bostan ve bahçelerde de üretimi yapılan domates, ${ }^{5} 1883$ 'te yayımlanmış olan Ev Kadını adlı yemek kitabındaki birçok tarifte yer almaktadır. Sekiz yüzden fazla tarifin yer aldığı bu yemek kitabında domates kırkı aşkın çorba, dolma, musakka, sebze tarifinde kullanılan bir malzemedir. ${ }^{6}$ Domates tüketimi 19. yüzyılın ikinci yarısında İstanbul mutfağında başlamış olsa da mutfakta yoğun bir şekilde salça ve domates kullanımı günümüzdeki kadar fazla olmamıştır. Domates ve domates salçasının Türk mutfağındaki kullanımı 20. yüzyılda, özellikle de savaş ve yokluk dönemlerinde artacaktır. Örneğin, 1919'da yayımlanmış olan Etsiz, Yağsız Tecrübeli Yemekler isimli yemek kitabında etsiz ve yağsız pişirilen sebze yemeklerini lezzetlendirmek için bu yemeklere bol miktarda soğan ve domates katıldığı görülmektedir.?

Amerika menşeli diğer ürünler arasında yer alan fasulye, sakız ve bal kabağı, yeşil ve kırmızı biber de İstanbul ve Osmanlı saray mutfaklarına 18. yüzyılın sonlarından itibaren girmiş ve tüketimi esas olarak 19. yüzyılda yaygınlaşmışıı. Kırmızı biber ilk olarak 18. yüzyıla ait bir tarifte, bir turşu tarifinde, yer almaktadır. ${ }^{8}$
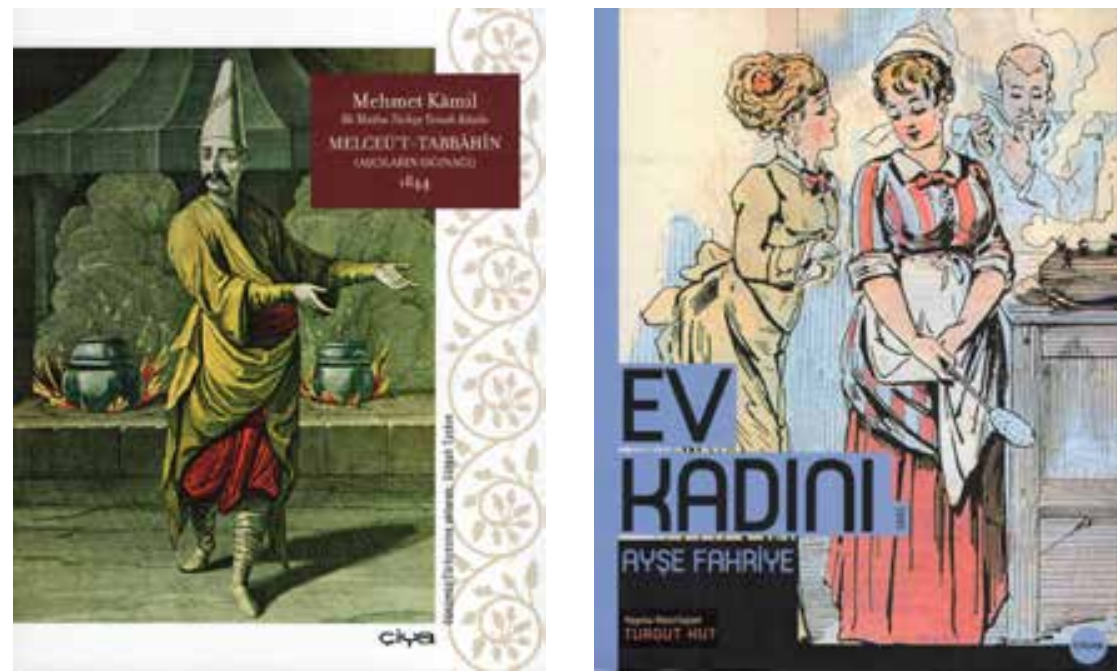

Mehmet Kâmil'in 1844, Ayşe Fahriye'nin 1883 tarihli yemek kitaplarının yeni baskıları 2016 ve 2018'de Çiya Yayınları'nca yapıldı.

4 Bkz. Mehmed Kâmil, Melceü’t-Tabbâhîn (İstanbul, 1844.)

51854 yılına ait saray mutfak defterlerine göre Feriye, Beylerbeyi, Çırağan, Ortaköy, Aynalı Kavak bostan ve bahçelerinden saraya gönderilenler arasında sakız kabağı, çalı fasulyesi, fasulye, biber, yeşil biberin yanı sıra yeşil domates ve kırmızı domates yer almaktadır. Bkz. BOA, Cevdet Saray, no. 257.

6 Ayşe Fahriye, Ev Kadını (İstanbul: Mahmud Bey Matbaası, 1883).

7 Hüseyin Hüsnü, Etsiz, Yağsız Tecrübeli Yemekler (İstanbul: Cemiyet Kütüphanesi, 1919). Metin çözümlemesi ve çevrimyazısı için bkz. Güldane Gündüzöz, "Mütareke Yıllarının İstanbulu’na Mutfaktan Bakmak”, OTAM 40 (Güz 2016): 279-302

8 M. Nejat Sefercioğlu, haz., Türk Yemekleri (XVIII. Yüzyıla Ait Yazma Bir Yemek Risalesi) (Ankara: Kültür ve Turizm Bakanlığı Milli Folklor Araştırma Dairesi Yayınları, 1985). 
Yeşil ve kırmızı biber 19. yüzyılda saray mutfaklarına alınan ürünler arasında yer almaya başlar. Kırmızı toz biber "Arnavut biberi” adı altında 1844 tarihli Aş̧ıların Sığınağı'nda seyrek olarak tariflerde yer alır; fakat hiçbir zaman kırmızı biberin verdiği acı tat İstanbul mutfağında baskın bir tat haline gelmez. Karnabahar ve yer elması sebzelerin sevilerek kullanııdı̆̆ı İstanbul mutfağında musakka, bastı ve zeytinyağlıların bir malzemesi haline gelir.

Mısır ziraatı Osmanlı coğrafyasında ilk olarak Balkanlar'da 18. yüzyılda başlamışıır. ${ }^{9}$ Mısır, “mısır-ı buğday" adıyla Osmanlı saray mutfak kayıtlarında ancak 1840'। yıllarda yer almaya başlar. ${ }^{10}$ Aynı dönemde bir başka Amerika kökenli sebze olan patates de saray mutfaklarına girmiştir. Az da olsa saray mutfaklarına özellikle yabancı konukların ağırlandığı alafranga usulde düzenlenen saray ziyafetleri için gerekli olan erzak alım listelerinde patatesin (patata) yer aldığı görülmektedir." Patates 1840'ı yıllarda Osmanlı damak tadı için hâlâ egzotiktir. Mehmed Kâmil, Aşçıarın Sığınağı'nda, patatesi bir çeşit yer elmasına benzetir ve patatesin İtalyan mutfağı kaynakı bir sığır yahnisi yemeği hazırlanmasında kullanılmasını önerir.12

Patates tüketiminin yaygınlaşması Adapazarı çevresinde 19. yüzyıl sonlarında ziraatının artmasıly birlikte, ${ }^{13}$ Birinci Dünya Savaşı ve Mütareke yıllarında İstanbul'daki yokluklarla ilişkilendirilebilir. Mütareke yıllarının yokluk dönemlerinde mutfak ekonomisini verdiği tarifler aracılığılla canlandıran Hüseyin Hüsnü, Etsiz, Yağsız Tecrübeli Yemekler kitabında patlıcan, domates, lahana ve yeşil biber dolmalarının tariflerinde et yerine iç malzeme olarak haşlanmış patates veya ekmek kullanılmasını önerir. ${ }^{14}$

Vanilya, kakao ve yenibahar seçkin Osmanlı mutfağında yine 19. yüzyıldan itibaren kullanılmaya başlanan tat vericiler arasında yer alı. ${ }^{15}$ Vanilya ve kakao alafranga kek, pasta ve tatlı yapımında kullanılır. Tüketimi sınırıdır. Çikolata alafranga tüketim kalıplarının yaygınlaştığı Pera bölgesindeki pastane ve kafelerde meraklısına bonbon, draje ve içecek olarak sunulur. Yenibahar tarçınla birlikte ilk olarak günümüzde olduğu gibi zeytinyağlı dolma içlerinin hazırlığında kullanııır.

Amerikan menşeli bitki bazlı ürünlerin Osmanlı mutfağına uyum süreçlerini dile getiren bu kısa yazının amacı, günümüz Türkiye'sinde var olan mutfak kültürünün zaman içinde yaşadığı değişimin bir çehresini aralamak ve mutfakta lezzet ve lezzet algısının değişken bir unsur olduğunu hatıllatmaktır.

9 Traian Stoianovich ve Georges C. Haupt, "Le maïs arrive dans le Balkans," Annales: ESC XVII (1962): 84-93.

10 BOA, CS, no. 6078, Receb 1259 (28 Temmuz-26 Ağustos 1843).

11 Samancı, La Cuisine d'Istanbul, 87-88.

12 Mehmed Kâmil, Melceü’t-Tabbâhîn, 33.

13 "Articles Spéciaux: Pommes de Terre", Revue Commerciale du Levant Bulletin Mensuel de la Chambre de Commerce Française de Constantinople (Constantinople: Imprimerie Française, Galata, Şubat 1897): 134-139.

14 Hüseyin Hüsnü, Etsiz Yağsız Tecrübeli Yemekler.

15 Samancı, La Cuisine d'Istanbul, 73-74. 